\title{
Energetic Aspects of Methanogenic Feeding Webs
}

\author{
BERNHARD SCHINK
}

The degradation of organic matter by methanogenesis is the most complex and the most efficient way of transforming organic matter into an energetically useful product. It is the dominant process in every anoxic environment where nitrate, sulfate, oxidized iron, or manganese species have been reduced, and where only $\mathrm{CO}_{2}$ is available as a terminal electron acceptor. Moreover, methanogenesis is the process of organic matter degradation that most likely evolved first in the Earth's biosphere and therefore had the longest time for evolutionary optimization. The complex interplay of different metabolic types (guilds) of microorganisms in the overall process represents an evolutionary strategy quite different from that of aerobic degradation. Whereas aerobic organisms typically oxidize complex organic substrates including polymers in one single cell all the way down to $\mathrm{CO}_{2}$ and inorganic residues with oxygen as electron acceptor, anaerobic degradative processes depend on cooperation between different guilds of microbes, and the complexity increases from nitratedependent over iron- or sulfate-dependent oxidation (typically a two-step process) to methanogenesis, in which at least three types of organisms have to cooperate for efficient substrate conversion.

The technological advantage of methanogenic degradation of biomass is obvious: a complex methanogenic community can degrade basically all types of major constituents of biomass, including polysaccharides, proteins, lipids, and nucleic acids finally to methane plus $\mathrm{CO}_{2}$, with few exceptions. The formed product, a mixture of methane, $\mathrm{CO}_{2}$, and traces of hydrogen sulfide, is gaseous and separates easily from the fermentation broth, without specific efforts involving distillation or transfer across membranes, etc. The advantage of methanogenesis over other fuel-producing processes becomes obvious from a comparison of energetics (all calculations are from tables published in Thauer et al., 1977):
Aerobic oxidation:

$$
\begin{aligned}
\mathrm{C}_{6} \mathrm{H}_{12} \mathrm{O}_{6}+6 \mathrm{O}_{2} & \rightarrow 6 \mathrm{CO}_{2}+6 \mathrm{H}_{2} \mathrm{O} \\
\Delta \mathrm{G}^{0^{\prime}} & =-2,870 \mathrm{~kJ} \text { per mol of glucose }
\end{aligned}
$$

Methanogenic fermentation:

$$
\begin{aligned}
\mathrm{C}_{6} \mathrm{H}_{12} \mathrm{O}_{6}+14 \mathrm{H}_{2} \mathrm{O} & \rightarrow 3 \mathrm{CH}_{4}+ \\
3 \mathrm{CO}_{2} \Delta \mathrm{G}^{0^{\prime}} & =-390 \mathrm{~kJ} \text { per mol glucose }
\end{aligned}
$$

As exemplified by these reactions, methanogenic conversion of biomass (using hexose as a representative) consumes only about $14 \%$ of the energy that is released in aerobic oxidation of sugar. The difference between the two is that $86 \%$ of the energy originally available in glucose oxidation is stored in the methane molecule and can be released later by burning this gas:

$$
\begin{aligned}
& 3 \mathrm{CH}_{4}+6 \mathrm{O}_{2} \rightarrow 3 \mathrm{CO}_{2}+6 \mathrm{H}_{2} \mathrm{O} \\
& \Delta \mathrm{G}^{0^{\prime}}=-2,480 \mathrm{~kJ} \text { per mol of glucose equivalent }
\end{aligned}
$$

Of course, biomass and other waste materials do not consist only of sugars. With proteins and, even more so, with lipids the overall redox balance shifts towards more methane than $\mathrm{CO}_{2}$ formation (reaction 4):

$$
\begin{array}{r}
2 \mathrm{C}_{16} \mathrm{H}_{32} \mathrm{O}_{2}+14 \mathrm{H}_{2} \mathrm{O} \rightarrow 23 \mathrm{CH}_{4}+9 \mathrm{CO}_{2} \\
\Delta \mathrm{G}^{0^{\prime}}=-385 \mathrm{~kJ} \text { per mol of palmitate }
\end{array}
$$

Thus, highly reduced compounds such as lipids, oils, fats, etc., are even better energy carriers in methane production than sugars and other biomass constituents, and the aerobic oxidation requires even higher amounts of oxygen, i.e., aeration in a conventional sewage treatment plant and, with this, higher waste treatment costs:

$$
\begin{array}{r}
\mathrm{C}_{16} \mathrm{H}_{32} \mathrm{O}_{2}+23 \mathrm{O}_{2} \rightarrow 16 \mathrm{CO}_{2}+16 \mathrm{H}_{2} \mathrm{O} \\
\Delta \mathrm{G}^{0^{\prime}}=-9,800 \mathrm{~kJ} \text { per mol of palmitate }
\end{array}
$$


It is for this reason that especially high-load organic wastewaters and semisolid waste materials have found their way recently preferentially into anaerobic, methanogenic treatment systems (Lettinga, 1995), and new treatment systems are being developed at present for treatment of average- and low-load municipal wastewaters (Aiyuk et al., 2006).

This chapter deals with the complex cooperations in methanogenic microbial communities under different treatment regimes and the technological perspectives in the optimization of energy recovery from biomass treatment in the present and in the future.

\section{THE BASICS}

Conversion of biomass to methane and carbon dioxide depends on a complex cooperation of numerous partner organisms of different metabolic capacities (Fig. 1). In this network, primary fermenting bacteria, often including strictly anaerobic protozoa, convert complex polymeric biomass (polysaccharides, proteins, nucleic acids, lipids, etc.) via their respective monomeric constituents (sugars and disaccharides, amino acids and oligopeptides, nucleosides, fatty acids, and glycerol) by fermentation to classical fermentation products such as $\mathrm{H}_{2}, \mathrm{CO}_{2}$, formate and other $\mathrm{C}_{1}$ compounds, acetate, and a series of reduced fermentation products including fatty acids, alcohols, succinate or lactate, aromatic fatty acids, and branched-chain fatty acids. Since the last partners in the overall process, the methanogens, use only very few substrates, namely $\mathrm{C}_{1}$ compounds, hydrogen, and acetate for methanogenesis, the majority of the classical fermentation products have to be further modified in so-called secondary fermentations to produce compounds that can be used by the classical methanogens.

The free energy available in the total methanogenic conversion of sugars (reaction 2) allows the synthesis of six ATP units at maximum, and the lion's share of this (up to four ATP units) is used up by the primary fermenting organisms, leaving only little energy for the partner organisms further down in the feeding chain.

The physiology and biochemistry of the secondary fermenting bacteria are of special interest because they have to live on an extremely small energy budget, catalyzing reactions that are endergonic under standard conditions and that are facilitated by close cooperation with the methanogenic partners which keep the con-

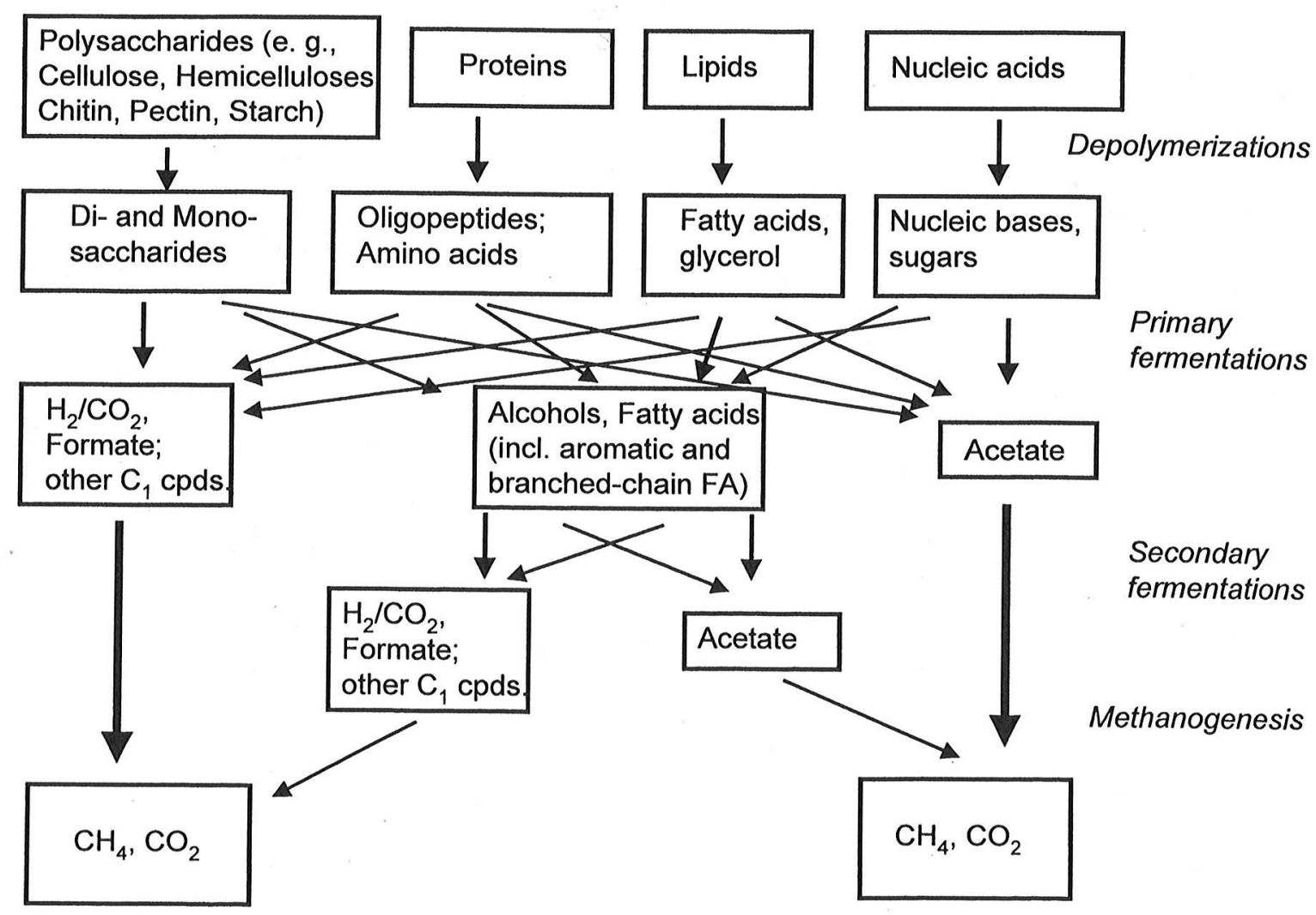

Figure 1. Network of the methanogenic feeding chain. Depolymerizations and primary fermentations are carried out by the same fermenting organisms. Note the decrease of chemical complexity with every step. 
Table 1. Changes of Gibbs free energy for secondary fermentations and methane-forming reactions

\begin{tabular}{lcc}
\hline \multicolumn{1}{c}{ Reaction } & $\Delta \mathrm{G}^{0^{\prime}}(\mathrm{kJ} / \mathrm{mol})$ & $\Delta \mathrm{G}^{\prime}(\mathrm{kJ} / \mathrm{mol})^{a}$ \\
\hline $\mathrm{CH}_{3} \mathrm{CH}_{2} \mathrm{OH}+\mathrm{H}_{2} \mathrm{O} \rightarrow \mathrm{CH}_{3} \mathrm{COO}^{-}+\mathrm{H}^{+}+2 \mathrm{H}_{2}$ & +9.6 & -41 \\
$\mathrm{CH}_{3} \mathrm{CH}_{2} \mathrm{CH}_{2} \mathrm{COO}^{-}+2 \mathrm{H}_{2} \mathrm{O} \rightarrow 2 \mathrm{CH}_{3} \mathrm{COO}^{-}+\mathrm{H}^{+}+2 \mathrm{H}_{2}$ & +48 & -26 \\
$\mathrm{CH}_{3} \mathrm{CH}_{2} \mathrm{COO}^{-}+2 \mathrm{H}_{2} \mathrm{O} \rightarrow \mathrm{CH}_{3} \mathrm{COO}^{-}+\mathrm{CO}_{2}+3 \mathrm{H}_{2}$ & +76 & -11 \\
$4 \mathrm{H}_{2}+\mathrm{CO}_{2} \rightarrow \mathrm{CH}_{4}+2 \mathrm{H}_{2} \mathrm{O}$ & -131 & -21 \\
$\mathrm{CH}_{3} \mathrm{COO}^{-}+\mathrm{H}^{+} \rightarrow \mathrm{CH}_{4}+\mathrm{CO}_{2}$ & -35 & -13 \\
\hline
\end{tabular}

${ }^{a}$ Under the following conditions: [acetate], $100 \mu \mathrm{M}$; [ethanol], [propionate], and [butyrate], $10 \mu \mathrm{M} ; \mathrm{CO}_{2}, 1 \mathrm{~atm} ; \mathrm{CH}_{4}$, $1 \mathrm{~atm} ; \mathrm{H}_{2}, 10^{-5}$ atm.

centrations of their reaction products (hydrogen, acetate, and formate) low. Some of these reactions are listed in Table 1, comparing energetics under standard conditions and under in situ conditions. It is obvious that these reactions can run and even provide energy for the catalyzing bacterium only under conditions of low product concentrations that are maintained by the methanogenic partners, and this specific type of symbiotic interrelationship has been termed "syntrophy." On average, these secondary fermentation reactions produce energy amounts in the range of -15 to $-25 \mathrm{~kJ}$ per mol, which is at the lowermost limit of energy increments that are needed to synthesize fractions of an ATP unit at all. If we assume that -60 to $-70 \mathrm{~kJ}$ is needed for synthesis of $1 \mathrm{~mol}$ of ATP under physiological conditions (Thauer et al., 1977), and if we assume, according to our present-day understanding of the membrane-bound $\mathrm{F}_{1} \mathrm{~F}_{0}$-ATPase apparatus, that 3 to 4 protons cross the cytoplasmic membrane per ATP unit formed or released, the minimum amount of energy required for ATP synthesis is equivalent to one-third to one-fourth of one ATP unit, i.e., -15 to $-20 \mathrm{~kJ}$ per mol (Schink, 1997; Schink and Stams, 2001). This is probably the minimum energy quantum needed for ATP synthesis in general, and there is no reliable report in the literature which documents that ATP is synthesized in growing cultures with smaller energy increments than this.

The mechanism by which syntrophically oxidizing bacteria organize their energy metabolism is only generally understood. The basic concept in those cases studied appears to be that one ATP unit per reaction run is synthesized by substrate-level phosphorylation, e.g., via phosphotransacetylase and acetate kinase in the release of an acetate residue. However, the bacteria cannot keep this full ATP unit but have to invest part of it into a reversed electron transport process in order to release electrons from unfavorable substrate oxidation steps at a comparably positive redox potential as molecular hydrogen (Fig. 2). Thus, part of this ATP unit is hydrolyzed again by a membrane-bound ATPase enzyme, thus providing a proton potential sufficient to drive a reversed electron flow towards hydrogen re- lease, and only a fraction of an ATP unit remains for biosynthetic purposes. This basic concept (Thauer and Morris, 1984) was demonstrated first with suspensions of intact cells of Syntrophomonas wolfei in butyrate oxidation (Wallrabenstein and Schink, 1994) and has been confirmed in more detail with the glycolateoxidizing bacterium Syntrophobotulus glycolicus. In the latter case, a tight coupling between glycolate oxidation, hydrogen release, and ATP hydrolysis could be shown convincingly with membrane vesicles (Friedrich and Schink, 1993). The reaction could even be reverted, as demonstrated through hydrogen- and glyoxylatedependent ATP synthesis with the same membrane vesicle preparations. In both cases, the coupling between the two steps was alleviated by protonophores (Friedrich and Schink, 1995), indicating that they are coupled via a proton gradient system. At least in propionate oxidation, also formate appears to play an important role as an electron carrier (de Bok et al., 2002).

The narrow range of energy available in the respective catalytic steps in the methanogenic feeding chain (not "food chain," because the bacteria do not eat each other) also explains why the concentrations of the

\section{Substrate}

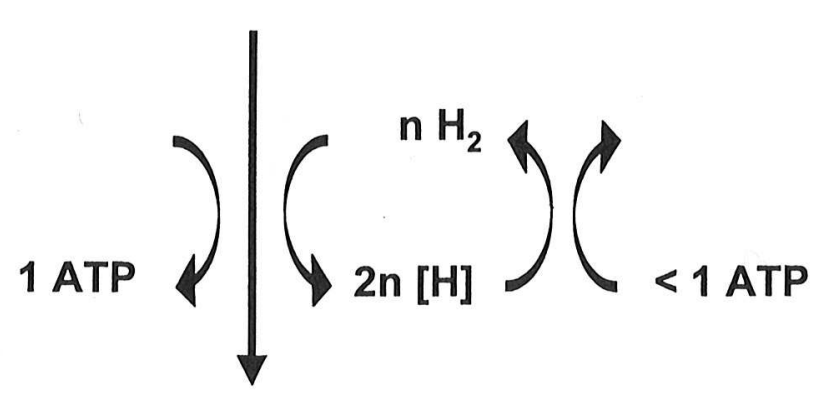

\section{Product(s)}

Figure 2. Basic concept of the energy metabolism of a syntrophically fermenting bacterium ("secondary fermenter" in Fig. 1). ATP is formed in the oxidative branch of the metabolism by substrate-level phosphorylation, and part of it is consumed in the release of electrons, e.g., as molecular hydrogen, in a reversed electron transport step. 
fermentation intermediates can change only within narrow ranges, i.e., 1 order of magnitude at maximum, because otherwise the energy budget for one of the individual partners in this feeding chain will become too low for ATP synthesis and, with that, for growth. This energetic limitation is also the main reason for the limited flexibility of methanogenic biomass degradation. Low energy yields in the secondary fermentations produce low amounts of biomass, thus causing slow growth and, with this, slow adaptation to environmental changes. These factors dictate that the elasticity of a methanogenic bioreactor is limited and that major fluctuations in feed composition are not always easy to balance. Although the rate-limiting steps in the overall processes are the depolymerization reactions at the beginning of the reaction chain, the terminal methanogenic reactions are the ones that determine the overall efficiency of electron flow through the inner versus the outer frame of the scheme in Fig. 1, and the methanogens are the "conductors" in the process (Zeikus, 1977). As long as hydrogen- and acetate-utilizing methanogens operate at high efficiency, the carbon and electron flow proceeds mainly directly towards acetate, $\mathrm{CO}_{2}$, and hydrogen, channeling only a small fraction of carbon and electrons to run through the central part (long-chain fatty acids etc.), which requires the energetically difficult secondary fermentations for complete degradation. If the hydrogen-utilizing methanogens are inhibited, for example, by increased acidity $(\mathrm{pH}<6.5)$, the product pattern of the primary fermenting organisms shifts to enhanced formation of long-chain fatty acids, and the further syntrophic oxidation of fatty acids is inhibited by enhanced hydrogen accumulation. This in turn leads to further accumulation of fatty acids, further acidification, and, finally, to entire reactor failure with little methane formation and accumulation of ill-smelling long-chain fatty acids ("reactor turnover"). On the other hand, the electron flow through the central part in Fig. 1 will never come down to zero because the degradation of lipids and amino acids necessarily forms straight- and branched-chain fatty acids of various chain lengths. Thus, the whole system has to be operated at a dynamic equilibrium, limited by the initiating reactions and conducted by the last players in the game.

Contrary to the concept of aerobic degradation of biomass, the basic concept of methanogenic degradation appears to be a resolution of functions into several small steps that are catalyzed by different types of microorganisms. So far, we have concentrated on sugars as a representative of biomass. However, biomass is far more complex, comprising a multitude of proteins composed of at least 20 different amino acids which each have separate pathways of anaerobic degradation, and the same is true for lipids, nucleic acid bases, aromatic residues, and many more (Fig. 1). It appears that the methanogenic degradation of all these different types of compounds is carried out by different microorganisms which cooperate in a complex network of separate modules that are performed by many different players. Obviously, the evolution of anaerobic degradative communities followed a strategy different from that of aerobic ones. The multitude of functions (catalytic steps and enzymes) needed for the degradation of complex biomass are not combined in one single organism, but in separate organisms which have to cooperate via metabolite transfer. The question arises as to why nature did not develop a methanogen that could grow on sugars or amino acids directly and, with this, combine a major part of the metabolic functions in one organism. Considerations on the efficiency of metabolic activities in long reaction chains suggest that separation into different organisms appears to be advantageous once too many reaction steps have to be lined up in a reaction sequence. Similar considerations were applied to the phenomenon that aerobic oxidation of ammonia to nitrate is always carried out by two separate bacteria acting cooperatively, never by one alone (Costa et al., 2006).

This modular arrangement of a complex cooperation network by partitioning functions into different organisms also requires that these organisms cooperate in a spatially optimized manner so that the diffusion distances for metabolites remain as short as possible. The implications of this strategy for the spatial arrangement of microbial communities have been discussed repeatedly (Schink, 1997), but no decisive answer has been found so far to the question of how optimally short diffusion distances are maintained in growing communities in which every single organism forms nests because it produces only offspring of its own.

\section{ALTERNATIVES}

\section{Hydrogen}

Energy-rich products other than methane can be produced fermentatively from biomass. Like methane, hydrogen is a gaseous product that easily separates from the fermenting broth. Nonetheless, fermentation of biomass to hydrogen has to face severe energetic limitations as exemplified here, again with glucose as a representative substrate:

$$
\begin{aligned}
\mathrm{C}_{6} \mathrm{H}_{12} \mathrm{O}_{6}+6 \mathrm{H}_{2} \mathrm{O} & \rightarrow 12 \mathrm{H}_{2}+6 \mathrm{CO}_{2} \\
\Delta \mathrm{G}^{0^{\prime}} & =-26 \mathrm{~kJ} \text { per mol of glucose }
\end{aligned}
$$

Up to now there is no organism known that would live with this small energy yield, transforming 12 elec- 
tron pairs to $12 \mathrm{H}_{2}$ molecules and still growing under these conditions. Instead, the sugar fermentation process with the highest hydrogen yield observed proceeds according to the following reaction:

$$
\mathrm{C}_{6} \mathrm{H}_{12} \mathrm{O}_{6}+2 \mathrm{H}_{2} \mathrm{O} \rightarrow 2 \mathrm{CH}_{3} \mathrm{COO}^{-}+2 \mathrm{H}^{+}+2 \mathrm{CO}_{2}
$$$$
+4 \mathrm{H}_{2} \quad \Delta \mathrm{G}^{0^{\prime}}=-216 \mathrm{~kJ} \text { per mol of glucose }
$$

Even this overall balance is reached only if the hydrogen partial pressure is kept low, e.g., by methanogenic partner organisms (see above). Under standard conditions, the free-energy change is not sufficient for the formation of four ATP units, which is intrinsically linked to this fermentation pattern through substratelevel phosphorylation in glycolysis (two ATP units) and acetate release in the acetate kinase reaction (a further two ATP units). The energetic situation improves at higher temperature, and thermophilic fermenting bacteria $\left(\right.$ at $\left.>70^{\circ} \mathrm{C}\right)$ may be better suited for catalyzing this process, especially since several thermophiles and hyperthermophiles ferment sugars through pathways different from glycolysis, with smaller ATP yields (Siebers and Schönheit, 2005). Indeed, enhanced hydrogen formation close to that described in equation 7 has so far been observed only with thermophiles (Claassen et al., 1999; Hallenbeck, 2005; Kanai et al., 2005).

Nonetheless, during this type of fermentation twothirds of the overall electron content of the sugar molecule remains in the two acetate molecules, from which hydrogen can be released only at very low hydrogen pressure:

$$
\begin{aligned}
\mathrm{CH}_{3} \mathrm{COO}^{-}+\mathrm{H}^{+}+2 \mathrm{H}_{2} \mathrm{O} \rightarrow & 2 \mathrm{CO}_{2}+4 \mathrm{H}_{2} \\
\Delta \mathrm{G}^{0^{\prime}} & =+96 \mathrm{~kJ} \text { per mol }
\end{aligned}
$$

This fermentation (inversion of homoacetogenesis!) becomes exergonic only at hydrogen pressures lower than $10^{-5}$ atm (Zinder and Koch, 1984) and cannot be applied efficiently for technical hydrogen production, therefore. It is the specific advantage of methanogenesis that it can transfer the electrons bound in acetate quantitatively to formation of methane, yielding sufficient energy for the respective bacteria involved for growth:

$$
\begin{array}{r}
\mathrm{CH}_{3} \mathrm{COO}^{-}+\mathrm{H}^{+} \rightarrow \begin{array}{c}
\mathrm{CH}_{4}+\mathrm{CO}_{2} \\
\Delta \mathrm{G}^{0^{\prime}}=-35 \mathrm{~kJ} \text { per mol }
\end{array}
\end{array}
$$

Therefore, only one-third of the overall electron freight of sugar (as representative of biomass in general) is released as hydrogen under optimal conditions, and the rest stays with the acetate which cannot be used as a fuel itself.

\section{Ethanol, Butanol, and Acetone}

Contrary to methane and hydrogen, the energyrich fermentation products ethanol, butanol, and acetone dissolve easily in an aqueous medium, and their recuperation from the medium always requires energyintensive separation efforts such as distillation, stripping, or vacuum treatment. Fermentation of a sugar solution with yeasts or with the bacterium Zymomonas mobilis produces fermentation broths with alcohol contents in the range of 10 to $12 \%$ ( $\mathrm{vol} / \mathrm{vol})$. For distillation of such a broth to reach an alcohol content of about $90 \%$, a substantial amount of energy is needed, which is in the same range as that finally available in the produced ethanol. Butanol and acetone fermentations reach even lower concentrations in the fermentation broth (4 to $5 \%$ ). Moreover, only a small part of biomass, especially monomeric sugars and di- and oligosaccharides, can be transformed to alcohols and acetone; starch fermentation already requires enzymatic pretreatment for this process. Other polysaccharides such as cellulose, hemicelluloses, proteins, and lipids are hardly ever accessible to alcoholic fermentation.

Obviously, the ethanol yield from specifically raised sugar-rich crop plants such as sugarcane, corn, or sugar beets is comparably high, but only minor parts of these plants are converted, and the remnants (leaves, stems, etc.) remain as waste products. Moreover, the efforts invested into the agricultural production of such energy plants have to be considered, including the unavoidable consequences of landscape devastation and soil degradation and erosion. For these reasons, production of energy-rich fermentation products should be confined primarily to the utilization of waste materials, including general household and industrial wastes and wastewaters, and methanogenesis appears to be the most efficient way of converting the majority of this waste biomass efficiently into an energy-rich product that separates easily from its broth origin.

\section{LIMITATIONS AND SOLUTIONS}

\section{Reactor Performance}

The enormous efficiency of the methanogenic feeding chain described above, which employs a complex network of many different metabolic types of microorganisms that perform their activities at a minimum gain of energy of about $-20 \mathrm{~kJ}$ per mol of reactionall this implicates certain limitations to methanogenic transformations in general. Compared to aerobic degradation processes, anaerobic transformations are usually considered to be slow. This is not necessarily true. The metabolic activity of single cells of strict anaerobes are not necessarily lower than those of aerobes 
if calculated per unit of cell protein; usually, we observe even for slow-growing anaerobes substrate transformation rates in the range of several hundred nanomoles per milligram of protein, which are similar to transformation rates for aerobes. However, the small energy gains, especially of some key groups in the feeding chain, imply that the cell yields for these organisms are low, i.e., that at similar substrate transformation rates only small cell yields can be obtained and that therefore the increase in biomass is slow. Thus, a methanogenic reactor system requires extensive start-up times for the establishment or reestablishment of a certain transformation process, and it will react only slowly to changes in the feed quality that require growth of new metabolic representatives (Schink, 1988). It is common practice in aerobic wastewater treatment systems employing the (aerobic!) "activated-sludge" process that the growing biomass is retained in the system through sludge recycling, thus maintaining a microbial community at about 10 times lower growth rates than the flow rate of the treated water (Schink, 1999). This sludge recycling uncouples growth of the active biomass in the activated sludge process from the wastewater flow through the system and allows also the maintenance of slow-growing microorganisms in the system, or of those which are needed only occasionally as a consequence of changes in the feed composition.

Of course, this necessity is even greater for an anaerobic waste treatment system due to the slow growth and low growth yields, especially of the secondary fermenting bacteria. Sludge recycling, analogous to the aerobic activated-sludge process, is not easy to apply in the strictly anaerobic world because the selection for easily settling sludge flocs in activated sludge depends on the presence of protozoa, especially ciliates, which graze preferentially on free-floating single cells and select for easily settling bacterial aggregates. Although strictly anaerobic flagellates and ciliates feeding on bacterial cells have been described, especially in nutrientrich, permanently anoxic environments (Embley et al., 1995), there is no indication so far that such organisms can be enriched and maintained in a productive manner in technical waste treatment systems.

Strategies to increase the retention time of microbes in a strictly anaerobic fermentor system have started with providing surfaces on which the microbial communities can establish themselves and thus can easily be withheld within the reactor. Depending on the waste load of the water to be treated, either fixed-bed reactors with low strength or fluidized bed reactor systems with high strength have been designed for this purpose, with varying success. A real breakthrough in the treatment of high-strength wastewaters was the development of the Upflow Anaerobic Sludge Blanket
(UASB) technology developed by G. Lettinga and his coworkers in Wageningen, The Netherlands, in the 1980s (Lettinga, 1995; Stams and Oude Elferink, 1997). This reactor type was developed primarily for the anaerobic treatment of high-load wastewaters, especially from the paper and fiber industry or from sugar manufacturing. Through a specific arrangement of separation blades in the upper part of the reactor, an efficient separation of gas bubbles from bacterial aggregates was obtained, and the aggregates grew to about $2 \mathrm{~mm}$ in diameter. These aggregates sedimented easily enough to be withheld and were retained in the reactor for sufficient times to maintain transformation efficiency and reactor performance stability. Although the reason for the development of these microbial aggregates remains obscure, the UASB technology has proven to be applicable to many different types of high-load wastewaters and has conquered the market in this field nearly worldwide. With this technology the major obstacle of anaerobic treatment processes, i.e., the slow growth of anaerobic microbial communities, could be overcome by maintenance of high densities of complex microbial communities for long periods. In a similar manner, methanogenic technologies can be applied for the treatment also of semisolid waste materials (Korner et al., 2003).

Besides methanogens, homoacetogenic bacteria and sulfate reducers can also cooperate in anaerobic fermentation, keeping the hydrogen partial pressure and the concentration of formate low and contributing to acetate formation and degradation. Obviously, sulfatereducing bacteria depend on sulfate as an external electron acceptor which is usually available only at limiting amounts, in the range of a few hundred micromolars at maximum. In certain cases, especially in the degradation of marine waste material (algae, chitin shells of shrimp, etc.) the high sulfate content of seawater leads to enhanced sulfate reduction which outcompetes methanogens for their key substrates. Enhanced proton activity, enhanced sulfate content, and enhanced ammonium concentrations, e.g., in treatment of poultry waste, all can impede the activity of hydrogen-oxidizing methanogens and, with this, the overall operation of a methanogenic bioreactor.

\section{One-Step versus Two-Step Technology}

From the discussion above, it should appear obvious that the efficiency of methanogenic transformations of biomass depends intrinsically on a close cooperation between all partners involved and that the maintenance of low hydrogen and acetate concentrations by the methanogens also improves the overall efficiency of all members in the game, including the primary fermenting bacteria, which under these conditions produce only 
small amounts of reduced intermediates. Nonetheless, some strategies in anaerobic biomass treatment prefer to run the primary fermentation first and quickly into an acidic stage and feed the reaction products of the first step slowly into a second, methanogenic step in which these classical fermentation intermediates are then degraded by syntrophic cooperations as described above. At first sight, such a strategy does not look promising because the efficiency of the primary fermenting organisms is soon inhibited by the accumulation of acids and other fermentation products. Nonetheless, operation of the process in two steps appears to be advisable in certain specific cases, such as in treatment of the easily fermented sugar-rich wastes of the sugar production industry. This offal becomes available only a few weeks per year at high amounts, and its methanogenic treatment would require for short periods high capacities of biogas reactors which are not needed for the rest of the year. In this case, it appears to be advisable to stabilize the primary waste materials by an acidogenic step at the time when they become available and to further treat the prefermented material in a medium-scale methanogenic biomass system over a longer period of time subsequent to the main sugar production campaign.

\section{Depolymerization of Biomass}

Polysaccharides including starch, celluloses, hemicelluloses, pectin, chitin, and many others as well as proteins, lipids, and nucleic acids are depolymerized extracellularly by the action of hydrolytic enzymes. With few minor exceptions, such hydrolytic depolymerases operate in the presence or absence of oxygen, basically through identical chemical strategies, no matter whether aerobic or anaerobic bacteria are involved. The situation is basically different with lignin, a polymer of aromatic residues which is produced by higher plants specifically as a solid structure able to resist microbial degradation for many years. The specialists for lignin degradation are fungi, especially white-rot fungi, which employ molecular oxygen in an extracellular lignin depolymerization reaction in which hydroxyl radicals attack the phenolic polymer in a random manner, releasing mono- and oligoaromatic derivatives (Leonowicz et al., 2001; Kirby, 2006; Baldrian, 2006). So far, there is no reliable indication that lignin can be degraded in the absence of oxygen at any substantial rate (Hackett et al., 1977). Unfortunately, lignin not only is a major constituent of wood but also is found in grasses and other green plant parts, of which it constitutes 10 to $20 \%$ (dry weight) of mass. Since lignin is typically tightly connected with the cellulosic and hemicellulosic parts of the plant cell wall, there is no easy way to separate lignin efficiently from the nonligninaceous plant material. Wood-feeding termites found an efficient way to separate them and utilize the cellulosic part of wood while excreting the lignin residues, but this process also requires oxygen as a cosubstrate (Brune and Friedrich, 2000). Thus, lignin is the key impediment in the degradation of organic matter, especially of residues of higher plants. This serious limitation of anaerobic degradation capacities is exemplified by the preservation of wooden ships and other wooden constructions in anoxic sediments, dating back to the Middle Ages, Roman times, and even to the Neolithic, i.e., more than 4,000 years ago. Technical strategies to destabilize the intrinsic linkages between lignin and cellulose in wood such as steam explosion have been applied successfully in paper manufacturing, but it is probably not feasible to apply this technology to lignocellulosic waste materials. So far, there is no convincing solution to overcome this obvious limitation of methanogenic degradation of natural biomass.

\section{Biochemical Challenges}

Our knowledge of the biochemistry of the anaerobic breakdown of low-molecular-mass derivatives of biomass has grown dramatically in the last 20 years. While textbooks in the 1970s still maintained the view that aromatic compounds cannot be degraded in the absence of oxygen, this view has changed dramatically, and there is hardly any type of compound that cannot be degraded in the absence of oxygen, including singlering aromatics, condensed aromatics (napththalene), aromatic and aliphatic hydrocarbons, straight- and branched-chain fatty acids, nitrogen- and oxygencontaining heterocycles, and many others. Halogen and nitro substituents can be removed reductively or hydrolytically in the absence of oxygen, and in some cases anaerobic, reductive approaches have proven to be more successful in the removal of such substituents than the strategies used by aerobic bacteria (Holliger and Schink, 1997). A whole new biochemistry has been discovered to be involved in the transformation of such comparably stable compounds, and contrary to earlier assumptions many of these reactions employ radical mechanisms (Spormann and Widdel, 2000; Boll et al., 2005; Buckel and Golding, 2006).

\section{CONCLUSIONS}

Methanogenic degradation of organic matter appears to be the superior process to convert the majority of organic waste materials to an energy fuel at high efficiency with respect to the overall fuel yields. In this respect, methanogenic degradation is far more efficient than other fermentative processes leading to hydrogen, 
ethanol, butanol, or acetone. All major constituents of living biomass or organic waste materials can be converted to methane plus $\mathrm{CO}_{2}$, with the only exceptions being lignin and lignocellulose. This high conversion efficiency is secured through the cooperation of many different types of fermentative bacteria and methanogenic archaeobacteria that accomplish the multitude of specific reactions converting the enormous diversity of major biomass constituents to less and less complex reaction intermediates by a modular arrangement of metabolic functions. Since the overall energy yield of methanogenic fermentation is small, only a very small amount of energy is available to the single organisms catalyzing its specific reaction step within this crossfeeding network. Several steps in this process yield just enough energy to supply the catalyzing organism with the absolute minimum of energy needed for ATP synthesis and growth, i.e., an energy amount in the range of -15 to $-20 \mathrm{~kJ}$ per mol reaction. It is this energetic efficiency that makes the overall process possible at all, but it also limits its kinetic and dynamic versatility.

\section{REFERENCES}

Aiyuk, S., I. Forrez, K. de Lieven, A. van Haandel, and W. Verstraete. 2006. Anaerobic and complementary treatment of domestic sewage in regions with hot climates-a review. Bioresour. Technol. 97:2225-2241.

Baldrian, P. 2006. Fungal laccases-occurrence and properties. FEMS Microbiol. Rev. 30:215-242.

Boll, M., B. Schink, A. Messerschmidt, and P. M. Kroneck. 2005. Novel bacterial molybdenum and tungsten enzymes: three-dimensional structure, spectroscopy, and reaction mechanism. Biol. Chem. 386:999-1006.

Brune, A., and M. Friedrich. 2000. Microecology of the termite gut: structure and function on a microscale. Curr. Opin. Microbiol. 3:263-269.

Buckel, W., and B. T. Golding. 2006. Radical enzymes in anaerobes. Annu. Rev. Microbiol. 60:27-49.

Claassen, P. A. M., J. B. van Lier, A. M. L. Contreras, E. W. J. van Niel, L. Sijtsma, A. J. M. Stams, S. S. de Vries, and R. A. Weusthuis. 1999. Utilisation of biomass for the supply of energy carriers. Appl. Microbiol. Biotechnol. 52:741-755.

Costa, E., J. Perez, and J. U. Kreft. 2006. Why is metabolic labour divided in nitrification? Trends Microbiol. 14:213-219.

de Bok, F. A., M. L. Luijten, and A. J. Stams. 2002. Biochemical evidence for formate transfer in syntrophic propionate-oxidizing cocultures of Syntrophobacter fumaroxidans and Methanospirillum hungatei. Appl. Environ. Microbiol. 68:4247-4252.

Embley, T. M., B. J. Finlay, P. L. Dyal, R. P. Hirt, M. Wilkinson, and A. G. Williams. 1995. Multiple origins of anaerobic ciliates with hydrogenosomes within the radiation of aerobic ciliates. Proc. Biol. Sci. 262:87-93.

Friedrich, M., and B. Schink. 1993. Hydrogen formation from glycolate driven by reversed electron transport in membrane vesicles of a syntrophic glycolate-oxidizing bacterium. Eur. J. Biochem. 217: 233-240.

Friedrich, M., and B. Schink. 1995. Electron transport phosphorylation driven by glyoxylate respiration with hydrogen as electron donor in membrane vesicles of a glyoxylate-fermenting bacterium. Arch. Microbiol. 163:268-275.
Hackett, W. F., W. J. Connors, T. K. Kirk, and J. G. Zeikus. 1977. Microbial decomposition of synthetic ${ }^{14} \mathrm{C}$-labeled lignins in nature: lignin biodegradation in a variety of natural materials. Appl. Environ. Microbiol. 33:43-51.

Hallenbeck, P. C. 2005. Fundamentals of the fermentative production of hydrogen. Water Sci. Technol. 52:21-29.

Holliger, C., and B. Schink. 1997. Anaerober Abbau organischer Schadstoffe, p. 83-90. In C. Knoll and T. von Schell (ed.), Mikrobieller Schadstoffabbau. Vieweg, Braunschweig, Germany.

Kanai, T., H. Imanaka, A. Nakajima, K. Uwamori, Y. Omori, T. Fukui, H. Atomi, and T. Imanaka. 2005. Continuous hydrogen production by the hyperthermophilic archaeon, Thermococcus kodakarensis KOD1. J. Biotechnol. 116:271-282.

Kirby, R. 2006 Actinomycetes and lignin degradation. Adv. Appl. Microbiol. 58:125-168.

Korner, I., J. Braukmeier, J. Herrenklage, K. Leikam, M. Ritzkowski, M. Schlegelmilch, and R. Stegmann. 2003. Investigation and optimization of composting processes-test systems and practical examples. Waste Manag. 23:17-26.

Leonowicz, A., N. S. Cho, J. Luterek, A. Wilkolazka, M. WojtasWasilewska, A. Matuszewska, M. Hofrichter, D. Wesenberg, and J. Rogalski. 2001. Fungal laccase: properties and activity on lignin. J. Basic Microbiol. 41:185-227.

Lettinga, G. 1995. Anaerobic digestion and wastewater treatment systems. Antonie Leeuwenhoek 67:3-28.

. Schink, B. 1988. Principles and limits of anaerobic degradation-environmental and technological aspects, p. 771-846. In A. J. B. Zehnder (ed.), Biology of Anaerobic Microorganisms. John Wiley and Sons, New York, NY.

Schink, B. 1997. Energetics of syntrophic cooperations in methanogenic degradation. Microbiol. Mol. Biol. Rev. 61:262-280.

Schink, B. 1999. Prokaryotes in environmental processes, p. 900912. In J. W. Lengeler, G. Drews, and H. G. Schlegel (ed.), Biology of the Prokaryotes. Thieme, Stuttgart, Germany.

Schink, B., and A. J. M. Stams. 2001. Syntrophism among prokaryotes. In M. Dworkin, S. Falkow, E. Rosenberg, K.-H. Schleifer, and E. Stackebrandt (ed.), The Prokaryotes: an Evolving Electronic Resource for the Microbiological Community, 3rd ed., SpringerVerlag, New York, NY.

Siebers, B., and P. Schonheit. 2005. Unusual pathways and enzymes of central carbohydrate metabolism in Archaea. Curr. Opin. Microbiol. 8:695-705.

Spormann, A. M., and F. Widdel. 2000. Metabolism of alkylbenzenes, alkanes, and other hydrocarbons in anaerobic bacteria. Biodegradation 11:85-105.

Stams, A. J., and S. J. Oude Elferink. 1997. Understanding and advancing wastewater treatment. Curr. Opin. Biotechnol. 8:328334.

Thauer, R. K., and J. G. Morris. 1984. Metabolism of chemotrophic anaerobes: old views and new aspects, p. 123-168. In D. P. Kelly and N. G. Carr (ed.), The Microbe, Part II. Prokaryotes and Eukaryotes. Cambridge University Press, Cambridge, United Kingdom.

Thauer, R. K., K. Jungermann, and K. Decker. 1977. Energy conservation in chemotrophic anaerobic bacteria. Bacteriol. Rev. 41:100180.

Wallrabenstein, C., and B. Schink. 1994. Evidence of reversed electron transport involved in syntrophic butyrate and benzoate oxidation by Syntrophomonas wolfei and Syntrophus buswellii. Arch. Microbiol. 162:136-142.

Zeikus, J. G. 1977. The biology of methanogenic bacteria. Bacteriol. Rev. 41:514-541.

Zinder, S. H., and M. Koch. 1984. Non-aceticlastic methanogenesis from acetate: acetate oxidation by a thermophilic syntrophic coculture. Arch. Microbiol. 138:263-272. 